\title{
Gastric ulcer following a thrombotic aneurysm of the splenic artery
}
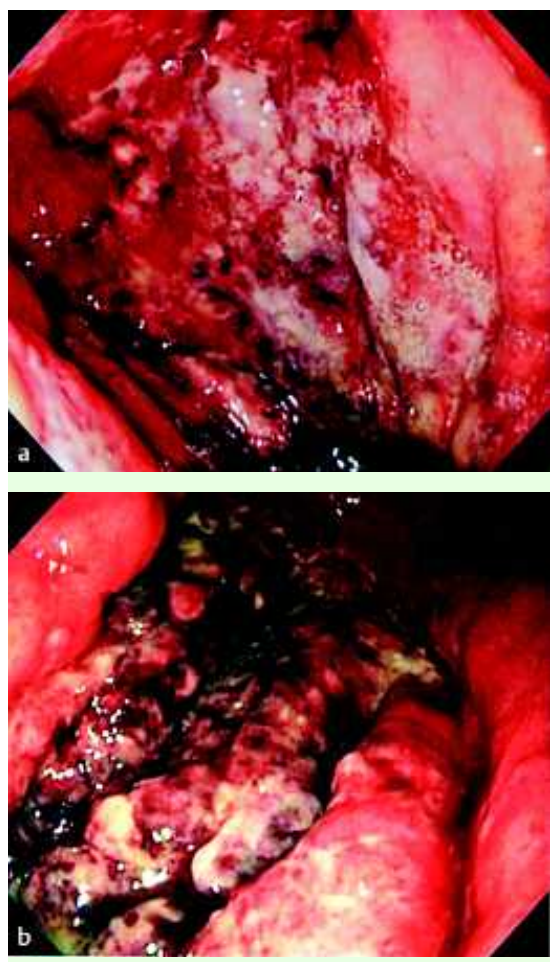

Fig. 1 Upper gastrointestinal endoscopy showing a segmental ulcer in (a) the fundus and (b) the body of the stomach.

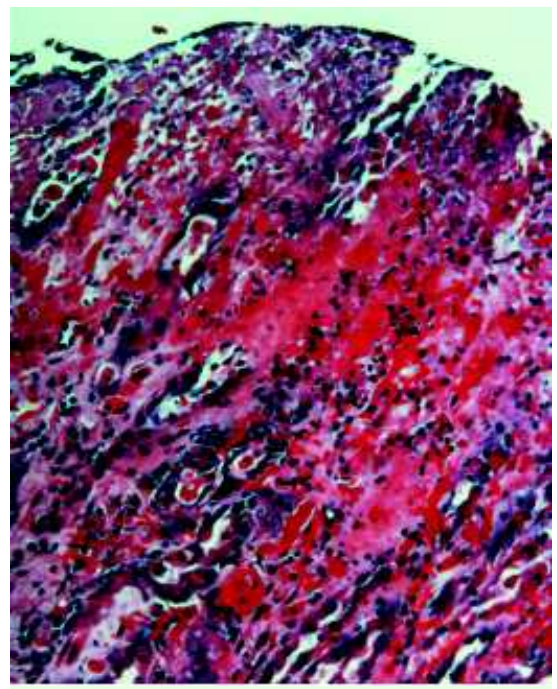

Fig. 2 Histological examination of the biopsy specimens revealing ulcerative superficial necrosis, edema and congestion. Hematoxylin and eosin stain; $\times 200$.

A 50-year-old man was admitted to our hospital with upper abdominal pain of sudden onset. He had a 10-year history of hypertension, but no history of peptic

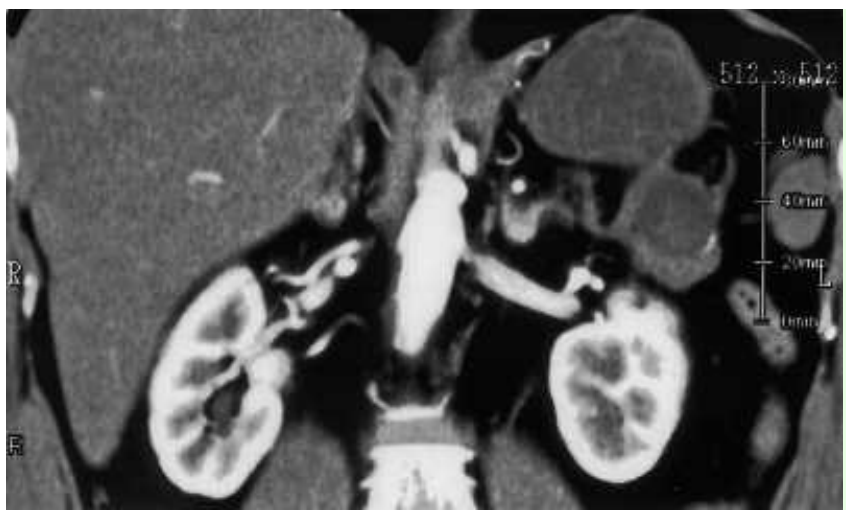

Fig. 3 Abdominal computed tomography showing a thrombotic aneurysm of the splenic artery.

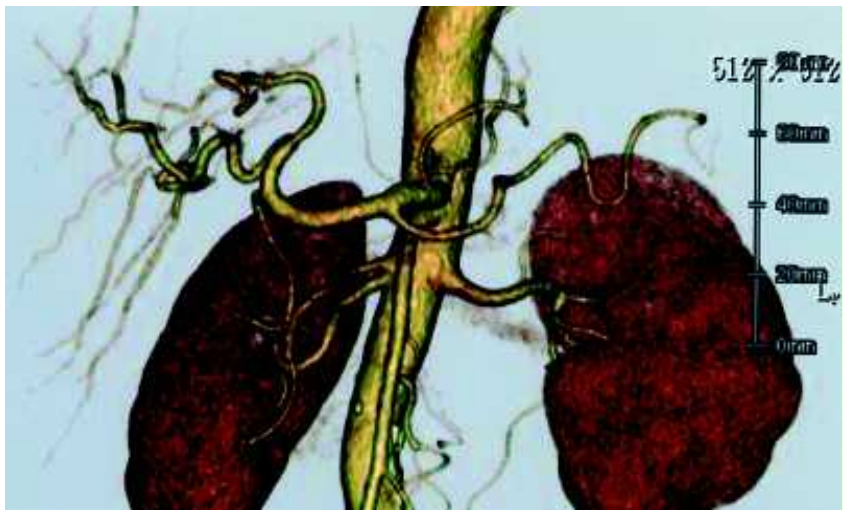

Fig. 4 Computed tomography (CT) angiography showing disruption of the splenic artery blood flow.

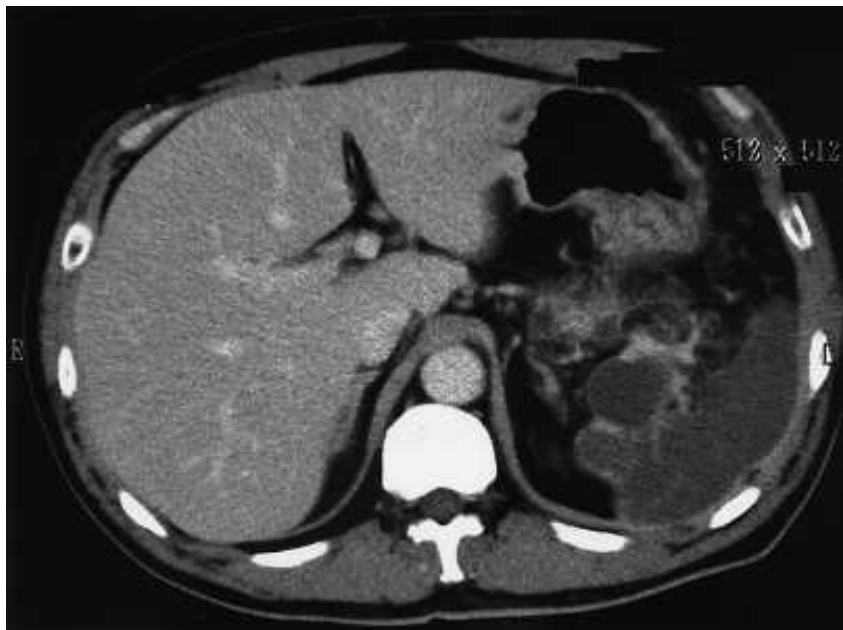

Fig. 5 Abdominal CT at 5 days following admission clearly demonstrating widespread splenic infarction.

ulcer, pancreatic disease, liver dysfunction, gastrointestinal operation, or use of nonsteroidal anti-inflammatory drugs (NSAIDs) or aspirin. The physical examination revealed severe tenderness in the upper abdomen. His white blood cell count was elevated to $14000 / \mathrm{mm}^{3}$; however, the other data were almost normal. An endoscopic examination revealed a segmental ulcer in the fundus ( $\bullet$ Fig. 1 a) and body of the stomach ( $\bullet$ Fig. $1 \mathbf{b}$ ). Histological examination of the biopsy specimens revealed ulcerative superficial necrosis, edema, and congestion ( $\bullet$ Fig. 2). Abdominal computed tomography (CT) and CT angiography showed a thrombotic aneurysm in the splenic artery and disruption of the splenic artery blood flow (- Fig. 3 and 4). Abdominal CT at 5 days following admission clearly revealed 
widespread splenic infarction ( $\bullet$ Fig. 5). The patient's symptoms and gastric ulcer gradually improved with conservative treatment, and he was discharged 30 days after admission.

Ischemic lesions of the stomach are very rare because of the stomach's rich vascular supply and extensive submucosal plexus. Gastric ulcers, caused by severe ischemia, have been reported as a late complication of gastric surgery, accompanied by splenic infarction, or following therapeutic embolization [1-3]. However, a gastric ulcer caused by a thrombotic aneurysm of the splenic artery is a very rare but serious complication.

Endoscopy_UCTN_Code_CCL_1AB_2AC_3AZ
K. Suzuki ${ }^{1}$, H. Takahashi ${ }^{2}$, N. Fujisawa ${ }^{1}$, Y. Sekino ${ }^{1}$, K. Akimoto ${ }^{1}$, A. Tomimoto ${ }^{1}$, K. Saito ${ }^{1}$, M. Yoneda ${ }^{2}$, M. Inamori ${ }^{2}$,

Y. Abe ${ }^{2}$, H. Kirikoshi' ${ }^{2}$, N. Kobayashi ${ }^{2}$,

K. Kubota ${ }^{2}$, S. Saito ${ }^{2}$, S. Koyama ${ }^{1}$,

A. Nakajima ${ }^{2}$

1 Department of Gastroenterology, Tokyo Metropolitan Hiroo Hospital, Japan

2 Gastroenterology Division, Yokohama City University School of Medicine, Japan

\section{References}

1 Kanetaka K, Azuma T, Ito $S$ et al. Gastric necrosis after an infarction of the spleen: report of a case. Surg Today 2003; 33: $867-$ 869

2 Bortul M, Scaramucci M, Tonello C et al. Gastric wall necrosis from organo-axial volvulus as a late complication of laparoscopic gastric banding. Obes Surg 2004; 14: 285 287

3 Bradley EL 3rd, Goldman ML. Gastric infarction after therapeutic embolization. Surgery 1976; 79: $421-424$
Bibliography

DOI $10.1055 / \mathrm{s}-2008-1077418$

Endoscopy 2008; 40: E193-E194

(c) Georg Thieme Verlag KG Stuttgart · New York . ISSN 0013-726X

Corresponding author

M. Inamori, MD

Gastroenterology Division

Yokohama City University School of Medicine

3-9 Fukuura, Kanazawa-ku

Yokohama, 236-0004

Japan.

Fax: +81-45-784-3546

inamorim@med.yokohama-cu.ac.jp 